\title{
"La guerra en Colombia dejó de ser el mecanismo adecuado para acceder al poder": Felipe Torres
}

\section{Entrevista a Carlos Velandia}

\author{
Por Mauricio Hernández Pérez
}

En Septiembre de 2012 el Gobierno Colombiano en cabeza del Presidente de la República Juan Manuel Santos, anunció el inicio de conversaciones con las Fuerzas Armadas Revolucionarias de Colombia (FARC) con el objetivo de buscar una salida política y negociada al conflicto armado.

La noticia fue sorpresiva, toda vez que la posibilidad de un acercamiento entre el grupo insurgente y la institucionalidad se planteaba como algo más bien lejano. Pese a esto, y en contra de todo pronóstico, hoy día y sin un cese bilateral del fuego, las conversaciones se suceden en La Habana Cuba sobre la base de la firma, por ambas partes, del denominado Acuerdo General para la terminación del conflicto y la construcción de una paz estable y duradera y en el que se contemplan algunos "mínimos" sobre los cuales las conversaciones han tenido, tienen y esperan continuar manteniendo desarrollo.

Los temas sobre los cuales este acercamiento ha avanzado es ya bastante conocido por la opinión pública; a saber: política de desarrollo agrario integral, participación política, fin del conflicto, garantías de seguridad, solución al problema de las drogas ilícitas, víctimas e implementación, verificación y refrendación. Sobre el primero de estos puntos ya ha habido acuerdos; sin embargo, la totalidad de los mismos (y de la agenda en su conjunto) sólo se conocerán hacia el final del proceso pues, como lo ha señalado el mismo Presidente Santos: "nada está acordado hasta que todo esté acordado".

Voces en pro y en contra del proceso no se han hecho esperar a medida que este avanza; e independiente de los resultados últimos que se obtengan, lo cierto es que la oportunidad por la que atraviesa el país para pensarse sobre algunos de sus temas estructurales es ahora más oportuna que nunca.

La negociación, sin embargo, se está dando únicamente con una de las fuerzas insurgentes hoy persistentes, y la posibilidad de incorporar o abrir un escenario de conversaciones futuro con el Ejército de Liberación Nacional (ELN) es más bien tímido aunque no del todo descartable.

Bajo este contexto, el Instituto para la Pedagogía, la Paz y el Conflicto Urbano, IPAZUD, entrevistó a Carlos Velandia (mejor conocido como Felipe Torres), Excombatiente del Ejército de Liberación Nacional (ELN) y quien contó en su momento con cargos de dirección en la agrupación durante la 
lucha clandestina. Este hombre dedicado hoy a la investigación por la paz y a la promoción de la misma, presenta en esta entrevista aspectos de su vida personal así como un balance general sobre las conversaciones entre el gobierno colombiano con las FARC, la situación "excepcional" en la que nos encontramos hoy en día, así como un análisis sobre la agenda en curso y las limitaciones e implicaciones que tiene un proceso de paz en Colombia sin contar con la participación del ELN. Si bien la opinión de este excombatiente no representa la posición oficial de la agrupación armada, sí da cuenta de algunos elementos interesantes en materia de construcción de paz por parte de una persona quien conoció y estuvo por dentro de la lucha armada, tanto en sus aspectos logístico-operativos, como en sus planteamientos ideológicos.

Palabras clave: ELN, FARC, agenda, paz, posconflicto.
Mauricio Hernández (M.H): Su historia personal y tránsito por el ELN fue retratada de manera completa en el libro de Jaime Jaramillo Panesso: Felipe Torres. La palabra sin rejas. Al haber quedado en libertad, después de diez años, y de haber cumplido condena en la cárcel de Itagüí por los delitos cometidos durante su actividad armada ¿Qué sucedió con su vida, qué aconteció después de lo narrado en este libro?

Carlos Velandia (C.V): Después de ese libro, sigue el exilio. Siete años de exilio. Estuve en Europa; principalmente en España. Llegué inicialmente a la ciudad de Granada, y allí me vinculé por invitación del Instituto de la paz y los conflictos de la Universidad de Granada. A esta institución me vinculé como investigador invitado. Allí tuve la oportunidad de tomar los cursos del Doctorado de paz, conflictos y democracia y empecé a mirar, desde una perspectiva diferente, muchos conflictos más en el mundo, pero también el fenómeno que es bastante reciente en la historia y es la construcción de teorías con relación a la paz y la investigación para la paz. Posteriormente me desplacé a Barcelona y me vinculé con la Escuela de Cultura de paz de la Universidad Autónoma de Barcelona; una institución que preside y fue fundada por un académico muy

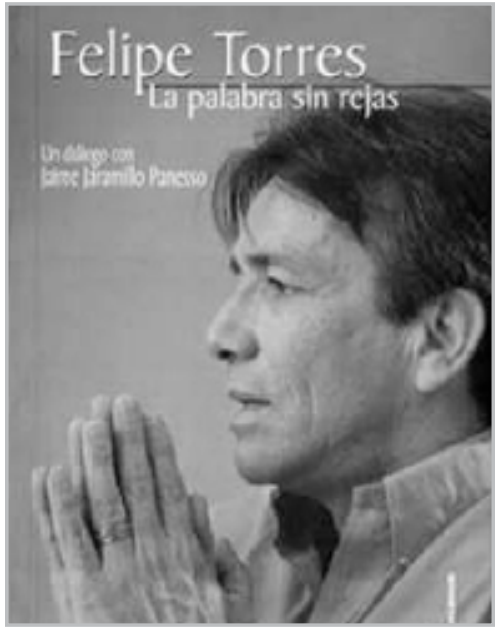

Portada del libro Felipe Torres. La palabra sin rejas.

reconocido y muy querido aquí en Colombia: Vicens Fisas. Allí tuve la oportunidad de introducirme en la investigación de conflictos de distinta índole, fundamentalmente me interesaban los conflictos internos. Constituimos un equipo con otros cuatro investigadores, tres de ellos colombianos y nos dedicamos tiempo completo a examinar día a día el acontecer del conflicto en Colombia y las distintas posibilidades de paz. Todo esto, para mí, alimentó la esperanza de que la paz en Colombia es posible y hoy lo estamos viendo. Tenemos una gran oportunidad que no debemos dejar escapar. 
(M.H): ¿Por qué decide regresar a Colombia?

(C.V): Se juntaron varios factores: siete años para un exilio son demasiado tiempo; cuando yo me fui para Europa nunca desempaqué la maleta; es decir, yo pensaba que debía regresar, lo que no sabía era cuándo. Se junta esta situación con la crisis en España, la crisis del capitalismo a nivel mundial y la manera como estremeció la economía europea, pero de manera particular a España. Esto llevó a que el gobierno tenía que optar por una política de recortes; el instituto al que yo estaba vinculado sufrió un recorte muy drástico en sus recursos. Esto me obligó a que yo tuviera que buscar otras perspectivas y estas perspectivas estaban aquí en Colombia. Pero al mismo tiempo también coincide con que en Colombia están cambiando las cosas y está en germen una gran oportunidad para la paz. Acabábamos de terminar una era de un largo gobierno de ocho años, de un gobierno que optó por la guerra, donde el discurso de la paz no era posible, e incluso era casi que criminalizado; pensar y expresar opiniones en favor de la paz, era lo menos que se podía pensar porque alguien que hablara de paz dentro de ese contexto era objeto de sospecha. Viene un nuevo gobierno, y Juan Manual Santos expresa de manera pública en su discurso de posesión que quiere hablar de paz y habla de una puerta abierta para la paz y habla de una llave; ese lenguaje simbólico reflejaba una disposición a abrir un espacio para el diálogo y la negociación que se complementa también con las expresiones públicas que hicieron el Ejército de Liberación Nacional y la guerrilla de las FARC, que también coincidió con un gobierno en plantear la necesidad de ese escenario.
(M.H): ¿Valió la pena la lucha armada? ¿Se justifica la lucha armada hoy?

(C.V): Yo no puedo deshacer la historia, tengo 61 años de vida y he dedicado a la lucha revolucionaria la mayor parte de mi vida. No reniego de mi pasado, ni más faltaba. Fueron decisiones que en su momento tomé de una manera muy consciente. Estimo, a la luz de los acontecimientos, y en la realidad de hoy, año 2013, que la guerra en Colombia dejó de ser el mecanismo adecuado, el mecanismo idóneo para intentar defender el poder o acceder al poder. La lucha armada seguirá teniendo una utilidad en determinados contextos, ya no en el contexto actual colombiano. Yo creo que la guerra en Colombia ha cumplido su papel, ha llegado al límite superior donde ya no es posible que ninguna de las partes derrote a su contendiente en el propósito, o de seguir defendiendo el statu quo, o de derrotar al contrario para acceder al poder. Esta fórmula ya no es posible. Esto, creo, es una de las razones que lleva a que las partes se hayan sentado a la mesa. Pero esta misma decisión también la han tomado las insurgencias, que son conscientes que por cincuenta años han obtenido un determinado nivel y acumulados, los que a mi juicio deben preservar y deben buscar potenciarlos en otro tipo de escenarios; en el escenario de la lucha políica, en el espacio de democracia ampliada. Ya no es posible seguir manteniendo esos acumulados a través de la guerra.

(M.H): ¿Qué diferencias encuentra entre el ELN al cual usted perteneció y el ELN de hoy día excluido de una mesa y de un proceso de negociación?

(C.V): El ELN es un continuo, no es estáti$\mathrm{co}$, ha sido una organización que la he visto 
crecer. Uno, porque fui un militante muy activo y en cierta forma hasta protagónico en la obra colectiva - no personal -de construir unos perfiles políticos, ideológicos y obviamente militares. Recuerdo que en un tiempo remoto hablábamos de la guerra popular prolongada; de la toma del poder. Yo soñaba, y me veía sentado en un tanque de guerra entrando a la plaza de Bolívar junto con una fuerza triunfante de ejército guerrillero y de insurrección social que nos tomábamos el poder y que empezábamos a construir una nueva sociedad: una sociedad socialista. De esas épocas a acá, ha corrido mucha agua bajo el puente, han pasado muchos años y obviamente, el país se ha transformado y las luchas también se van modificando. EI ELN, a mediados de los años ochenta, evoluciona en su pensamiento y pasa de una propuesta de toma del poder a construcción del poder desde ya,desde donde seamos más fuertes. Allí los revolucionarios estamos obligados a propugnar por transformaciones. Empezamos entonces a funcionar en algunas partes, en algunas regiones del país donde no estaba el Estado, ahora el Estado éramos nosotros. Pero al mismo tiempo también se hace una progresión muy interesante y es que el ELN desdobla su poder en el poder del pueblo y plantea que el pueblo habla, y el pueblo manda; es decir, ya no es el poder para el ELN; es el poder del pueblo y para el pueblo. Entonces estos son factores que muestran cómo se modifica un pensamiento, cómo evoluciona de manera positiva.

Al día de hoy, obviamente el tema del poder del pueblo y para el pueblo sigue teniendo plena vigencia en el ELN en la aspiración por una sociedad socialista, pero sigue teniendo mucha más vigencia en lo inmediato; en el inmediato futuro, en la construcción de mita una serie de transformaciones para el país que le lleven bienestar y le lleven justicia social a las gentes.

Podríamos decir entonces que el concepto de democracia adquiere mucho más valor. Ya hubo una época donde el ELN valoraba, por ejemplo, la inutilidad de los procesos electorales; la mirada sobre la lucha electoral que hoy tiene el ELN es distinta, es mucho más cualificada, mucho más contemporánea. Entonces estos son aspectos muy progresistas en la formulación de las ideas, al punto que me llevan a mí a decir que una de las razones por las cuales yo dejo la lucha armada para continuar defendiendo el ideario "Eleno" a través de la lucha política y creo que es posible seguir defendiéndola en un espacio de democracia ampliada.

(M.H): ¿Y qué diferencias encuentra entre el ELN y las FARC? ¿Considera usted que estas diferencias han sido determinantes para que hoy día se entable un proceso de diálogo y negociación con las FARC y no con el ELN?

(C.V): Lo determinante es sin lugar a dudas, la correlación de fuerzas. Desafortunadamente aquí en Colombia pesan más los actos de fuerza, los actos de violencia que las mismas ideas. La sociedad ha tenido que acudir a los expedientes de fuerza para poder expresar sus ideas o siquiera para arrancar algún tipo de demanda, algún tipo de conquista; esto es desastroso en una democracia y mucho más desastroso en una democracia como la que se desarrolla en Colombia que es una democracia formal.

Las FARC es una organización nacional que opera en vastos territorios de la geografía del país; ha estado presente en la vida política y en la historia de estos últimos cincuenta años. Sin embargo, las FARC no han 


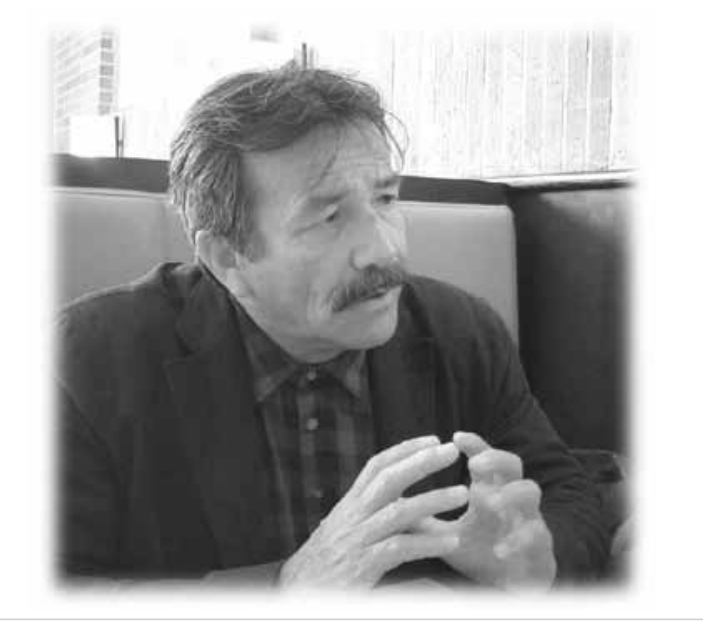

Foto: María Isabel Parra - IPAZUD

logrado "capturar" la agenda del país y esto ha generado una situación, podríamos decir, un tanto asimétrica; las FARC han desarrollado una estrategia evidentemente militar aunque no necesariamente la política haya estado ausente-;y sus desarrollos han sido fundamentalmente militares.

Ahora, en el caso del ELN es un tanto contrario;sus argumentos políticos y su protagonismo a través de las ideas, a través de las tesis, es el mayor de sus esfuerzos y su empeño militar es una parte menor a lo largo de la historia.

Esto al momento de intentar resolver el conflicto armado establece unas prioridades. Esa situación es la que vemos reflejada ahora en la mesa de La Habana.

(M.H): Para la época en que Álvaro Uribe Vélez estuvo en la Presidencia, el ELN mostró más avances con el gobierno en materia de conversaciones; incluso se consolidó un formato de acuerdo denominado el "acuerdo base" ¿Qué características tuvo este acuerdo?

(C.V.): Este acuerdo base es un acumulado que representa un gran trabajo entre un Estado y una organización insurgente. Ojalá no se perdiera, yo creo que allí hay cosas que son bastante útiles; no aconsejo retomarlo en su totalidad porque han cambiado los tiempos, pero sí creo que es posible actualizar este acuerdo base y ponerlo en el contexto actual.

Yo creo que sigue teniendo plena vigencia la convención nacional, que está planteada también en el acuerdo base. Creo que también tiene plena vigencia un cese bilateral de fuegos. Es doloroso que cuando estamos hablando de paz se incrementen las acciones bélicas y se esté produciendo mucho más dolor. Es injustificable, pero así están planteadas las reglas del juego, las reglas de la guerra: hay que seguir matando hasta el último día, hasta antes de la firma, esa es una lógica desafortunada y perversa, pero esa es. Entonces yo sí creo que el acuerdo base es posible retomarlo pero para actualizarlo.

(M.H): ¿Qué insumos de este acuerdo base podrían ser útiles ante un eventual proceso de negociación hoy día entre el gobierno y el ELN? ¿Qué otras ideas de este acuerdo se pueden rescatar para el proceso actual con las FARC?

(C.V): Los contenidos que se plantean para la convención nacional son cinco bloques temáticos. El primero, donde están las reformas al Estado y el fortalecimiento de la democracia para propiciar la inclusión de los excluidos y permitir la expresión de las mayorías. El segundo, el modelo de desarrollo económico. El tercero, recursos y soberanía; que es un bloque muy importante y sobre todo en este momento cuando se plantea que la economía ha de tener una locomotora minera; es decir, la locomotora de saqueo, del expolio de los recursos por parte de las multinacionales. El otro tema tiene que ver con los territorios, la territorialidad y el tema 
de la tierra que está siendo abordado en la mesa de La Habana pero no en su totalidad. $Y$ un quinto tema es, nuevamente, el de soberanía, pero que tiene que ver con cómo podríamos ser una nación, un país respetable y respetado y cómo nos lograríamos relacionar de una manera libre con el mundo entero sin necesidad de que tengamos que ser considerados como el patio trasero.

(M.H): Usted sostiene que este es el último proceso de negociación al cual entra el país en tanto las condiciones están dadas. ¿Cuáles son esas condiciones a las cuales usted hace referencia? ¿No es esto un exceso de optimismo?

(C.V): Bueno, usted habla de demasiado optimismo. Los constructores de paz y los que trabajamos estos temas de la paz hemos de ser optimistas por naturaleza porque si nos cunde la derrota, si nos absorbe la derrota, no haríamos absolutamente nada. La paz es de tercos, es de persistentes, es de consecuentes y obviamente es de optimistas. Pero el optimismo mío es un optimismo razonado, es un optimismo con argumentos, es un optimismo objetivizado en situaciones concretas.

Nunca antes como ahora, el gobierno ha sido tan explícito en plantear la solución política al conflicto y dar pasos en esa dirección. Nunca antes como ahora, la guerrilla de las FARC ha tomado una decisión política de poner fin al conflicto. Al mismo tiempo, nunca antes como ahora, la sociedad colombiana está diciendo: apoyamos este proceso pero que nos lleve al final del conflicto, y nunca antes como ahora la comunidad internacional ha rodeado este proceso donde ya no solamente es un grupo de países sino también Naciones Unidas, la Unión Europea y el
Al mismo tiempo aquí en América Latina nuestro continente hoy por hoy es cuna de revoluciones; es el único continente donde hay cuatro revoluciones en curso: la revolución socialista en Cuba, la revolución Bolivariana en Venezuela, la revolución ciudadana en Ecuador y la revolución comunitaria en Bolivia. Es donde se está produciendo pensamiento para resolver los grandes problemas en los contextos latinoamericanos, mientras que en Europa el pensamiento para resolver los grandes problemas no encuentra salida. El pensamiento político y filosófico europeo ha llegado a su tope y no se recrea. Antes las ideas que movían las revoluciones en el mundo venían de Europa, ahora yo creo que América Latina le va a contribuir al mundo con tesis revolucionarias y tesis de transformación. Entonces son nuevos contextos, son nuevas situaciones. Y las guerrillas también han comprendido que hay que intentar otras vías para acceder a las transformaciones como lo están haciendo los pueblos en América latina.

Todas estas son razones que en conjunto me hacen ver que es la oportunidad; no es una oportunidad más, es LA oportunidad para de una vez por todas poner fin al conflicto armado de cincuenta años; que de lograrlo no será un episodio, será EL acontecimiento.

(M.H): Algunos analistas han venido desarrollando la tesis según la cual, ante un eventual acuerdo de paz entre las FARC y el Gobierno, y la no negociación con el ELN, el afianzamiento operativo y militar de esta agrupación y de otros actores armados será inevitable, dando lugar así a nuevas violencias incontrolables por lo cual el conflicto se perpetuaría. ¿Comparte usted esta tesis? 
(C.V): Es un escenario que no es descartable, pero no necesariamente debe ocurrir así; el riesgo que hay al hablar con una sola organización y dejar a la otra en las montañas es que la paz, en primer lugar, sea incompleta; segundo,que sea una paz parcial; tercero, que sea una paz única y exclusivamente localizada en algunos territorios mientras que en otros se mantiene la guerra.

Ahora, esto le daría pie al estado para seguir manteniendo el alto nivel de gasto militar; unas fuerzas armadas tan impresionantes en volumen a las que han llegado; cerca de medio millón de efectivos entre hombres y mujeres al servicio de la violencia institucional y de la guerra. Colombia está gastando, diariamente, sesenta y ocho mil millones de pesos. Si el conflicto, lográramos superarlo, no habrá razón para mantener ese nivel tan alto en el gasto militar. No abra razón para seguir manteniendo unas fuerzas armadas tan voluminosas y de estas proporciones. Es más, esto nos posibilitaría reducir las fuerzas armadas, profesionalizarlas.

Ahora, este planteamiento no es en contra de las fuerzas armadas; va en favor del país. El país tal vez necesite unas fuerzas armadas profesionales, tecnificadas, educadas, con una nueva doctrina de civilidad, de protección de los recursos, de defensa de las fronteras, de defensa de la soberanía y de protección y cuidado del ciudadano.

Unas fuerzas armadas, si las logramos reducir a la mitad podrían llevarnos a nosotros, al Estado colombiano, a liberar al menos, setenta mil millones de pesos diarios, y podemos invertir en educación, salud, vivienda, en las necesidades que tiene la sociedad para procurar el bienestar y la justicia social. Es decir, es cambiar la guerra por desarrollo, la paz es desarrollo, es justicia social, a eso es que hay que apostarle ahora. Yo creo in- cluso que los militares entienden esto. El discurso mío no es en contra del estatuto militar, ni más faltaba, no es en contra de los generales; al contrario, es en favor de su profesionalización, de su tecnificación, es colocar a los militares en un escenario distinto de un país en paz.

(M.H): ¿Por qué cree usted que hay oídos sordos por parte del gobierno para escuchar al ELN en una mesa de negociación? ¿Hay una suerte de "calculo"?

(C.V): Yo creo que es una mezcla de dos cosas; obviamente el cálculo está en la elaboración de la estrategia. El gobierno está desarrollando una estrategia de paz y esa estrategia de paz nos lleva a hablar con la organización más fuerte militarmente mientras que a otras expresiones armadas las deja aparte.

No tengo claro si realmente el gobierno ha tomado la decisión de incluir en esa estrategia de diálogo al ELN. El Presidente ha expresado públicamente y ha llamado al ELN a que se suba a la mesa, pero del lado del gobierno no se ven muchas acciones en esa dirección. El ELN todos los días y cada vez que tiene la oportunidad está llamando, "oiga aquí estamos, si es para la paz cuenten con nosotros, queremos disposición". Entonces esto es una situación que a mí me genera mucha preocupación y es que puede ocurrir que en el momento que el gobierno decida que ya es la hora de hablar con el ELN quizás para ese momento el ELN puede valorar que prefiere esperar un momento políico distinto, con otro gobierno, quizás. Eso podría ocurrir y sería lamentable. Yo lo he dicho en un artículo que publicaron en revista semana y que se titula: "en la demora está el peligro". Retomo una frase de Eloy Alfaro en la que plantea que en las oportunidades hay que 


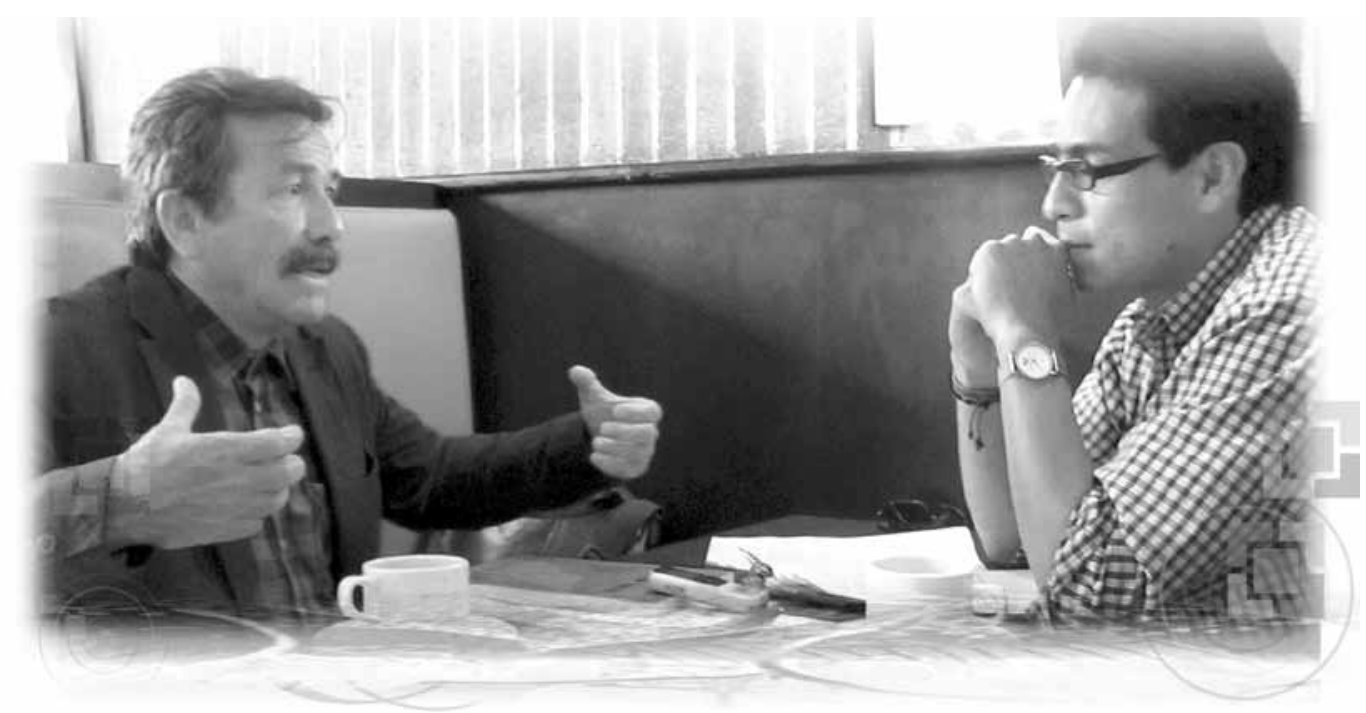

Foto: María Isabel Parra - IPAZUD

estar, en el momento justo, en el momento adecuado. $Y$ este es el momento justo, el momento adecuado. Tengo entendido que algunos expertos y algunos consejeros han aconsejado al gobierno para que desarrollen un proceso únicamente con las FARC; que no es conveniente abrir dos frentes de diálogo porque podría haber interferencias de uno sobre el otro. Yo creo que técnicamente es conveniente tener este tipo de precauciones, pero se corre un riesgo también bastante alto y es dejar en la guerra y dejar en las montañas a una organización que curiosamente ha sostenido un diálogo con todos los gobiernos -aun con el más belicoso; con el que ofrecía guerra y hacía la guerra - y este, que habla de paz, le vaya a voltear la espalda, sería bastante contradictorio.

(M.H): Centrándonos en los puntos de negociación que se discuten en La Habana hoy día, ¿Qué diferenciaría una agenda del ELN de una agenda de negociación de las FARC? ¿Qué relación, en términos de agenda, puede hacer entre estas dos agrupaciones?
(C.V): Yo creo que en el contexto actual no es posible una agenda de carácter maximalista y creo que no es posible la gran agenda que se planteó en los diálogos con el gobierno de Pastrana; eso ya no es posible porque ya hay otra realidad.

El conflicto en estos últimos doce años ha tenido un impacto y un efecto en las partes que, llevadas también por este balance de correlación de fuerzas, produce un efecto en las agendas. En los conflictos internacionales y en los conflictos internos hay un fenómeno de elasticidad; la agenda se alarga o se recorta dependiendo de la correlación de fuerzas. Si tú vas ganando la guerra tu agenda será más grande, que fue lo que pasó con Pastrana; en el gobierno de pastrana las FARC ganaban la guerra, por eso su agenda de trece grandes puntos y cien subpuntos daban cuenta de la correlación de fuerzas. Este no es el caso; la correlación de fuerzas ha llevado a que la agenda se acote.

No creo yo que el ELN pueda pactar una agenda mayor que la que ha logrado las FARC con el gobierno.

Yo creo, puedo estar equivocado, que una agenda posible para el ELN sería tomar 
como diseño básico la misma agenda de La Habana y sería -quizás suene un poco rudo lo que voy a decir- hacer un "corte y pega"; cortar en el punto uno donde dice: desarrollo rural y el tema agrario, y el cuarto punto donde dice: cultivos de uso ilícito y en su remplazo pegar en el primer punto: desarrollo mineroenergético y soberanía, y en el cuarto punto participación de la sociedad y democracia. Los demás puntos son comunes para las dos organizaciones y el Estado en el propósito de llegar a un final del conflicto armado.

\section{(M.H): ¿Qué evaluación le merece el proce- so de La Habana hasta lo que lleva hoy día?}

C.V: Recientemente escribí un artículo que se titula "las cuatro patas de la mesa" en el que planteo que una mesa de negociación se soporta sobre cuatro grandes pilares 0 cuatro patas: la primera pata, que las partes expresen claramente que asumen el diálogo y la negociación con un propósito muy claro y que se comprometen con ese propósito: el final del conflicto armado; esa pata allí está y es muy sólida.

Segundo, que haya una agenda concreta, una agenda alcanzable y una agenda que en términos prácticos pueda ser discutible y susceptible de llegar a acuerdos.

Tercero, que haya una sociedad dispuesta a apoyar este proceso de paz, que acompañe este esfuerzo y que reclame de la mesa y que reclame de ese proceso unos resultados y que al mismo tiempo haya una comunidad internacional que esté arropando el proceso.

$Y$ en cuarto lugar que haya resultados a la vista; es decir, que se demuestre que el proceso de diálogo es útil, que se está llegando a resultados y que la gente y la comunidad internacional observen que la paz es posible, que un acuerdo está cercano y que vale la pena seguir persistiendo en la discusión y en el proceso de paz.

Para mi es fundamental las expresiones de apoyo que se han venido desarrollando desde diferentes sectores de la sociedad en favor del proceso, en favor del acuerdo que sobre tierras se ha alcanzado.

Pero también mucho más importante y mucho más disiente que el Presidente Lula Da Silva, que la Unasur en pleno,que el Presidente Maduro, que el Vicepresidente Joe Biden de los Estados Unidos vean bien encaminado el proceso, que Naciones unidas, que el señor Van Rompuy del Concejo Europeo, que el Señor Durão Barroso, que el Expresidente Felipe González de España, pero al mismo tiempo Rodríguez Zapatero expresen estos apoyos es muy disiente de la seriedad y del tenor de este proceso y de los resultados que se están alcanzando.

(M.H): ¿Por qué este capítulo de la paz que estamos experimentado hoy día no es un proceso más entre la dinámica de la confrontación y la negociación a la que se ha visto abocada la sociedad colombiana en su historia?

CV: Hay una gran diferencia de este proceso respecto del proceso que se desarrolló hace ya trece años. Ese proceso que se desarrolló con Pastrana, ambas partes fueron a la mesa no a hacer la paz sino a ganar la guerra, es curioso. Es decir, Pastrana va a una mesa de diálogo y negociación con el discurso de la paz, y las FARC van a la mesa de diálogo y negociación con el discurso de la paz, pero ambos tenían propósitos distintos.

Pastrana va en representación del Estado derrotado, que está sufriendo unos golpes terribles por parte de las guerrillas; y las FARC van como la organización triunfante que quie- 
re legitimar ante el Estado sus acumulados y sus victorias ante la comunidad internacional. Es decir, ninguno va allí buscando poner fin al conflicto armado; van con propósitos distintos y desarrollan estrategias diferenciadas.

Mientras que estaban en el Caguán Hablando hasta la extenuación sin abordar ni un solo punto de la agenda, el Presidente Pastrana convertía un ejército derrotado en un poderoso ejército que le heredó al Presidente Uribe para que pudiera obtener las victorias militares que obtuvo.

La situación de ahora es que con un ejército tan poderoso y con unos recursos tan impresionantes no fue posible derrotar a las guerrillas, y hay que buscar un camino distinto y es el de la solución política negociada. Obviamente las guerrillas de hoy no son las guerrillas de hace trece años, ni cuantitativamente ni en su poder de letalidad, ni en su poder bélico. Pero en esto nos podemos pasar veinte o treinta años más.

(M.H): Usted actualmente se encuentra haciendo consultorías en materia de paz y conflictos. Desde esta perspectiva, ¿cómo evalúa el papel de la academia en los aspectos relacionados con el análisis del conflicto armado y la construcción de paz en el país?

(C.V): Yo diría que hay más literatura en relación con los conflictos y la violencia que sobre la paz. La investigación por la paz en el mundo es relativamente joven; no tiene más de sesenta años. Se empieza a hacer investigación sobre la paz y a establecer métodos y a establecer recursos; incluso a desarrollar pedagogías sobre investigación para la paz y cómo hacer paces pero sólo después de la segunda guerra mundial. Es una disciplina en el campo de la investigación y las ciencias sociales muy nueva.

Obviamente nuestros académicos preocupados por el conflicto colombiano son mucho más profusos y escriben mucho más sobre el conflicto porque esta ha sido la tendencia universal; escribir sobre las guerras, escribir sobre los muertos, escribir sobre la violencia; es decir, hay mucha más literatura sobre esto que sobre las paces. Y aquí en Colombia escribir sobre las paces si es que es verdaderamente nuevo. Yo creo que aquí no tenemos más de veinte años de literatura sobre paces y nos falta hacer mucho más.

Pero todavía nos falta, más que escribir, desarrollar pedagogías para la construcción de paz, para la generación de cultura de paz, para el sostenimiento de la paz, que es una tarea que tendrá que venir de manera inexorable en el posconflicto.

(M.H): Concluyamos esta entrevista con una frase que, para usted, refleje o capture el momento en el que nos encontramos hoy día.

(C.V): La paz es ahora. 